\title{
A critical analysis on the Blue Ocean Strategy and an approach for its integration into the Product Development Process
}

\author{
Josmael Roberto Kampa, Carlos Czivlik, Carla Cristina Estorilio Amodio \\ Federal University of Technology of Paraná State \\ e-mail: czivlik@utfpr.edu.br
}

\begin{abstract}
A study on the Product Development Process (PDP), the Strategic Planning Process (SPP) and the Blue Ocean Strategy (BOS) has been developed in order to verify the scientific strengths of the BOS and its integration mechanisms into the PDP. The conducted study has been based on an exploratory and qualitative research, a field survey with a company that advocates using BOS, and an attempt to interview the proponents of BOS. The study indicates that the BOS approach, as proposed in the book of Kim and Mauborgne (2005), requires additional procedures to be fully implemented into companies developing products. Additionally, the BOS integration into a PDP can occur through a list of ideas for new products, which can be derived from the BOS formulation, at the SPP stage, following the model proposed by Kaplan and Norton (2008). Due to the limited evidences obtained, as well as, the practical limitations of a controlled test (which would involve a large amount of variables) the scientific strengths of BOS could not be validated. Mental maps that structure the work of Kim and Mauborgne (2005) and its correlations with PDP have been developed and contribute to better understanding the practical limitations observed.
\end{abstract}

Keywords: blue ocean strategy, product development process, strategic process planning.

\section{Introduction}

According to Cooper (2001), differentiation, as a key issue for a company success in the market, is a recurring theme in many studies on the new products development. This author states, from a study he conducted, that offering more value per unit of money and having a competitive price are essential to success. Results indicate that the exclusive practice of low price has not shown a positive impact on the success of new products. In this context, there is the concept of differentiation of value as a business strategy. This is widely advocated by authors such as Trout and Rivkin (2000), Ries and Trout (2002), Trout (2005) and Kotler and Keller (2006). Considering that products demand differentiation and low costs, an approach developed by Kim and Mauborgne (2005), called Blue Ocean Strategy (BOS), proves challenging, since it suggests differentiation and low cost should be addressed simultaneously. Despite the demand for an approach of this type, it has not yet been identified links between the theory from Kim and Mauborgne (2005) with the Product Development Process (PDP).

Thus, the objective of this paper is to show the preliminary results from a research that seeks to produce a critical analysis over the scientific adherence of BOS as well as the feasibility of its integration into PDP. This paper progresses as follow. Section 2 explores main characteristics of PDP, Strategic Process Planning (SPP) and BOS. Section 3 describes the methodology devised to carry out the research. A critical analysis of BOS as well as the proposed model to integrate BOS with SPP and PDP is described in Section 4. Section 5 contains the discussion over the main results from this research. Finally, Section 6 contains the closing remarks about the findings in this work.

\section{Development of new products and Blue Ocean Strategy}

\subsection{Product development process}

According Rozenfeld et al. (2006), the ability to overcome the challenges when developing new products depends substantially on the model adopted as a reference to the PDP, for planning the project itself and developing the demanded programs. According to these authors, a reference model of a process is a symbolic representation that describes: i) the activities; ii) expected results; iii) who is responsible for what; iv) available resources; v) support tools; and vi) information necessary and/or generated in the process.

However, despite numerous references on PDP subject, its pre-development activities (also called Fuzzy Front End (FFE)) are poorly structured. Comparatively, FFE is not supported by a clear structure involving steps, tasks and tools, such as occurs in the models from Pahl et al. (2005), Rozenfeld et al. (2006) and Back et al. (2008), practiced worldwide and in Brazil. It is known that the 
pre-development activities have peculiarities that still need to be studied so they can be systematized. The correlated fields of research involve examining: entrepreneurship, marketing, strategic planning, among others.

Additionally, in companies' practices, opportunities for developing new products occur randomly, usually as ideas for new products. From this scope, a decision is taken to move forward or abort the development. This opportunity identified is fed opportunity is fed into a PDP model adopted by the company, with the aim at guiding the project planning through the product commercialization. Authors like Rozenfeld et al. (2006) and Back et al. (2008), indicate the SPP as a main component of the front end of a PDP model. The transition from SPP to the PDP is discussed next.

\subsection{Strategic planning process}

The search of detailed information about SPP, identified that references such as Mintzberg, Ahlstrand and Lampel (2000) and Mintzberg et al. (2006), considered classics on the strategy subject, presented a thorough overview on the theme. However, they do not provide a reference model for strategic process planning, such as Rozenfeld et al. (2006) does for the design process. The work from Kaplan and Norton (2008) comes closer to the aim of structuring a reference model for SPP. These authors propose a system to integrate strategic planning with its operational execution. The system has six major stages: i) develop the strategy; ii) plan the strategy; iii) align the previous items with the organization; iv) planning the operations; v) monitoring and learning; and vi) testing and adapting. The authors suggest that this same cycle will be deployed to the Business Units (BUs) and Functional Units (FUs), inside the corporation. Thus, the FU that should develop the product would use the same structure to develop its strategy, based on the BU strategy that derives its scope from the corporate strategy.

In the model by Kaplan and Norton (2008), in stage 1, managers can formulate a strategy based on a set of strategic tools, which one of them can be BOS. Following, in stage 2, the organization plans a strategy based on tools such as strategy maps and Balanced Scorecards (BSCs), clearly defining the strategic issues, the strategic objectives for each theme as well as the indicators and targets. Here, also are defined the strategic initiatives (programs or projects at corporate level) needed to accomplish the main goals, as well as, allocated the demanded resources. Among these strategic initiatives, it may be placed a project for developing new products. Finally, in stage 3, managers use internal operational data and new information about the external environment and competitors, including analysis of new opportunities, to test and adapt the strategic hypothesis. This can start a new cycle over the integrated strategic planning process and its operational implementation.
Thus, BOS can be used to formulate the strategy and to guide the definition of strategic initiatives to be undertaken on specific projects, at all levels of the organization. Some of these projects can be the new products. Next section discusses how BOS can provide a strategic direction. On the other hand, it is highlighted that the process involves the generation and improvement of new product ideas. In other words, the BOS requires the definition of strategic initiatives related to new products or services.

\subsection{Blue ocean strategy}

The BOS is aimed at systematically identifying "blue oceans", characterized by: i) unexplored markets; ii) capable of creating market demands; and iii) highly profitable growth for the company, (KIM; MAUBORGNE, 2005). The main differences between the strategic postures considering a "blue ocean" and a "red ocean", can be seen in Table 1 .

The first characteristic can be mapped into the guidelines proposed by Trout and Rivkin (2000), Ries and Trout (2002) and Trout (2005), which state that a product should not compete in existing categories. The second characteristic contains the foundation of strategic thinking from BOS. Instead of devoting energy and creative efforts on how to overcome a competitor, a company should formulate means to break the existing paradigm and better serve the customer. Thirdly, the company should present a new paradigm to the client, who now should consume the new product and/or stop purchasing the existing products and services. This occurs because existing products/services offer low value to the client, even if the previous offers contain a basic benefit. In this way, a company can capture non-customers and customers that buy from the competition. The fourth and fifth characteristics for establishing differentiation present a non-conventional reasoning for most companies, which is: generating more value directly implies a substantial increasing in costs. Therefore, companies should seek means for breaking this status by identifying ways to deliver value to the customer with a low cost approach. The BOS is a

Table 1. Main differences between Red Ocean Strategy versus Blue Ocean Strategy.

\begin{tabular}{|l|l|}
\hline \multicolumn{1}{|c|}{ Red Ocean Strategy } & \multicolumn{1}{c|}{ Blue Ocean Strategy } \\
\hline $\begin{array}{l}\text { Compete in existing market } \\
\text { space }\end{array}$ & $\begin{array}{l}\text { Create uncontested market } \\
\text { spaces }\end{array}$ \\
\hline Beat the competition & $\begin{array}{l}\text { Making the competition } \\
\text { irrelevant }\end{array}$ \\
\hline Exploit existing demand & Create and capture new demand \\
\hline Exercise the cost-benefit trade-off & Break the cost-benefit trade-off \\
\hline $\begin{array}{l}\text { Align the whole system of } \\
\text { the company's activities with } \\
\text { its strategic choice for either } \\
\text { differentiation or low cost }\end{array}$ & $\begin{array}{l}\text { Align the whole system of the } \\
\text { company's activities in pursuit } \\
\text { of both differentiation and low } \\
\text { cost }\end{array}$ \\
\hline
\end{tabular}

Souce: Addapted from Kim and Mauborgne (2005). 
strategy that focuses on both, differentiation and low cost. Pahl et al. (2005, p. 51) comment that the simultaneous pursuit of differentiation and low cost is an extreme strategy, which is acquiring significant importance, considering the fierce competition in global markets nowadays.

The methodological approach of the BOS is composed by: i) analytical tools; ii) models; and iii) principles of formulation and implementation. According to the authors the tools and analytical models are used for creating and capturing blue oceans (i.e. creating and prospecting unexplored market spaces; new demands of highly profitable growth). They are: i) The Strategy Canvas; ii) The Four Actions Framework; iii) The New Value in The Strategy Canvas; iv) The Eliminate-Reduce-Raise-Create Grid; v) Three Characteristics of a Good Strategy. Its implementation follows the principles of strategy formulation and execution, guiding the process of BOS. According to Kim and Mauborgne (2005), there are six principles for guiding the formulation and implementation of BOS: i) reconstruct market boundaries; ii) focus on the big picture, not the numbers; iii) reach beyond existing demand; iv) set the strategic sequence right; v) overcome key organizational hurdles; vi) build execution into strategy. These six principles are detailed in the body of the book and respond for almost $52 \%$ of its content. However, it is not possible to depict if these tools should be used sequentially. A model that could represent the working flow and interrelation of activities is omitted. Next, the research approach is presented.

\section{Methodology}

The research approach adopted in this work is presented in Figure 1 and detailed in the following paragraphs.

Initially, an exploratory review on the themes PDP, SPP and BOS was deployed. Additionally, Conventional
Mechanisms for Opportunity Identification (CMOI) were studied. At this stage, classical works from Urban and Hauser (1993), Cooper (2001), Koen et al. (2001, 2002), Fiet, Clouse and Norton Junior (2004), Ko (2004), Cooper and Edgett (2007), Kelley and Littman (2008), Stull, Myers and Scott (2008) were carefully examined. Following, a case study was planned, involving a company that claims applying BOS principles. This company designs and manufactures electro-electronics products in its Curitiba plant. To strength the analysis, a structured interview was designed to be conducted with the BOS developers and/or consultants. However, there was only one participant from the targeted company that provided information. Moreover, the BOS authors and consultants inquired, contacted by BOS international network, were unwilling to participate. Thus, the amount of practical information about the BOS and its relationship with the PDP and SPP was limited. To overcome this drawback, a practical BOS case was identified and studied. This case was available in the Brazilian BOS Portal (KIMBERLY-CLARK, 2009).

This set of information was the basis for the development of two mind-mappings, which provide support for the aimed critical analysis. For producing these maps, six topics were considered: i) operational procedures; ii) inputs and outputs; iii) differences from CMOI and the Theory of Opportunities Identification; iv) scientific characteristics of BOS; v) relevant features mapped into SPP and PDP; vi) mechanisms for opportunities identification available at BOS. Next section, presents the main results obtained with the analysis conducted.

\section{Results}

The main result of this research is the analysis presented in the next sections. The works from Rao (2007) and Owen (2009) provided the framework for the reasoning involved.

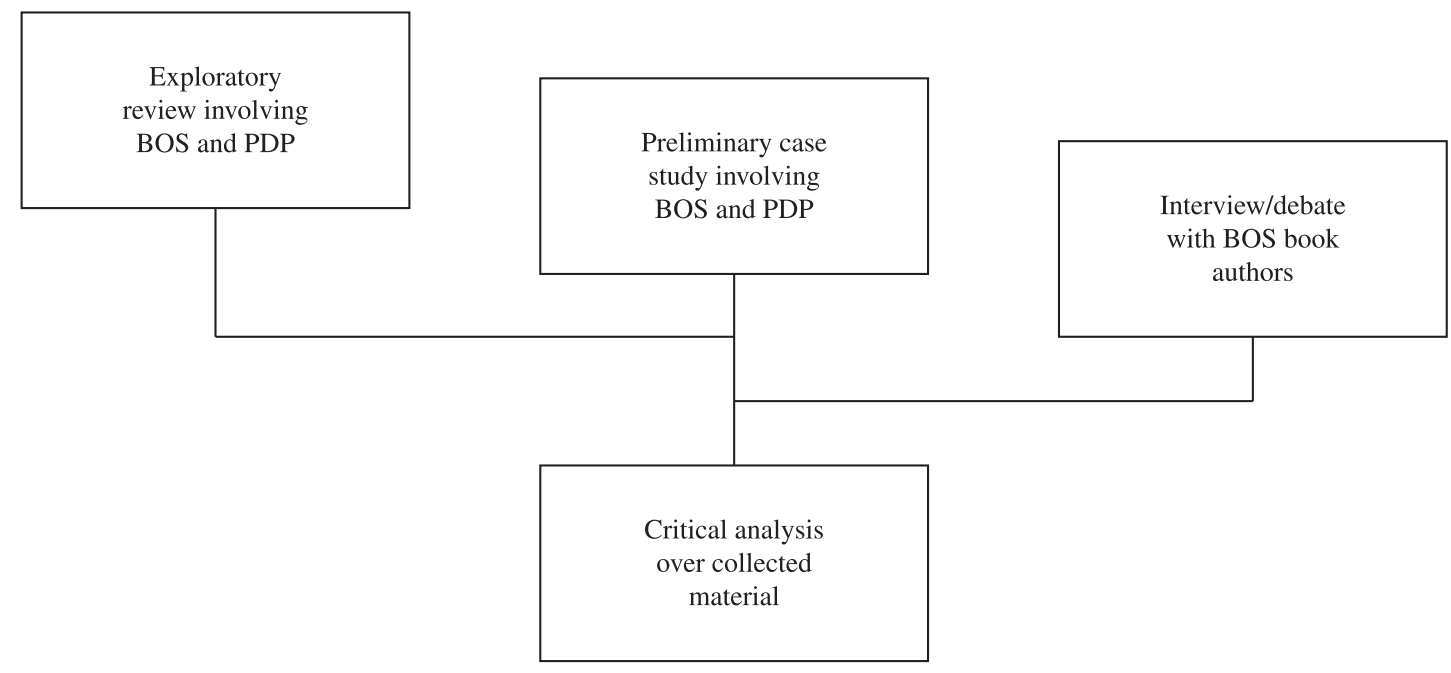

Figure 1. Proposed methodological approach. 


\subsection{Critical analysis of the BOS}

It can be observed from the guidelines presented by Kim and Mauborgne (2005) are not sufficient for a complete BOS implementation into practice. Also, there is not a clear link between the BOS formulation principles and its execution. There are gaps that should be explained to provide a strong support for BOS usage. This lack of clarity and practical evidences is also identified by Rao (2007).

Additionally, there is not a clear definition of which should be the inputs and expected outputs. It is inferred that BOS starts its course of action from information derived from a red ocean, a problem shared by the individuals that define a particular market and configure a sector that requires an offer. Therefore, BOS analyses the problem identified, as well as, evaluates both the market and the sector. The output is in the form of a strategic profile that guides all actions to be taken by the company in order to be successful in the market, making the competition irrelevant. This strategic profile drives the creation and selection of these actions, which may have been generated by insights during the profile preparation. The strategic profile generated is vulnerable, since it is linked to what the market expects to receive as well as to what the sector fails to offer nowadays. Therefore, there are two variables changing constantly.

The BOS differs from the conventional thinking present is some CMOI, like those found in Urban and Hauser (1993). BOS seeks to restructure the niches currently served by available products. Thus, it can be said that BOS does not create new demand, but changes the profile of the existing demand by capturing buyers from different slots. It is believed, these buyers stop purchasing the offers directed to a specific niche. As an example: i) a wine maker can produce a wine that looks like a beer and cocktails; ii) an air company devises a service that looks like a car, train and bus, everything at the same time. Therefore, buyers that migrate from the original offer are captured as well as those derived from this unexplored offer (that present attributes of value in common). From that, it can be inferred that the main characteristic of BOS is of de-segmentation, which differs from the conventional practice of segmentation (Figure 2).

The target market is reconstructed by existing affinity on the attributes of value and value gaps identified when targeting certain markets. The BOS inquiries the structure established and redefined its scope, as means for creating attributes of differentiation. This can lead to a definition of an unexplored market. However, there were no evidences that support this inference. Actually, what it is perceived is that the value gap occurs in practice when there is a disruption between supply and demand rather than creating an offer.

Note that the BOS explores the boundaries of known opportunities, existing in red oceans. BOS does not start from scratch, but a chaotic environment, especially those with well-defined competition. This starting point is determined by an existing company. BOS does not suggest the prospection of sector where the proposed approach can be applied. Those companies that decide to implement BOS are supposed to define the sectors of interest. From the point of view of an entrepreneur this can be a problem.

The BOS model does not indicate another starting point than the sector to which the company already operates. An entrepreneur, who has not yet established a company, does not receive any guidance on where to begin. In the literature about entrepreneurship, exploring different sectors can be a market opportunity that has somehow been identified. The BOS model does not address serendipity or the examination of unexplored markets. Thus, BOS does not present a specific stage for opportunity identification. The authors treat this issue sparsely in the approach, calling it

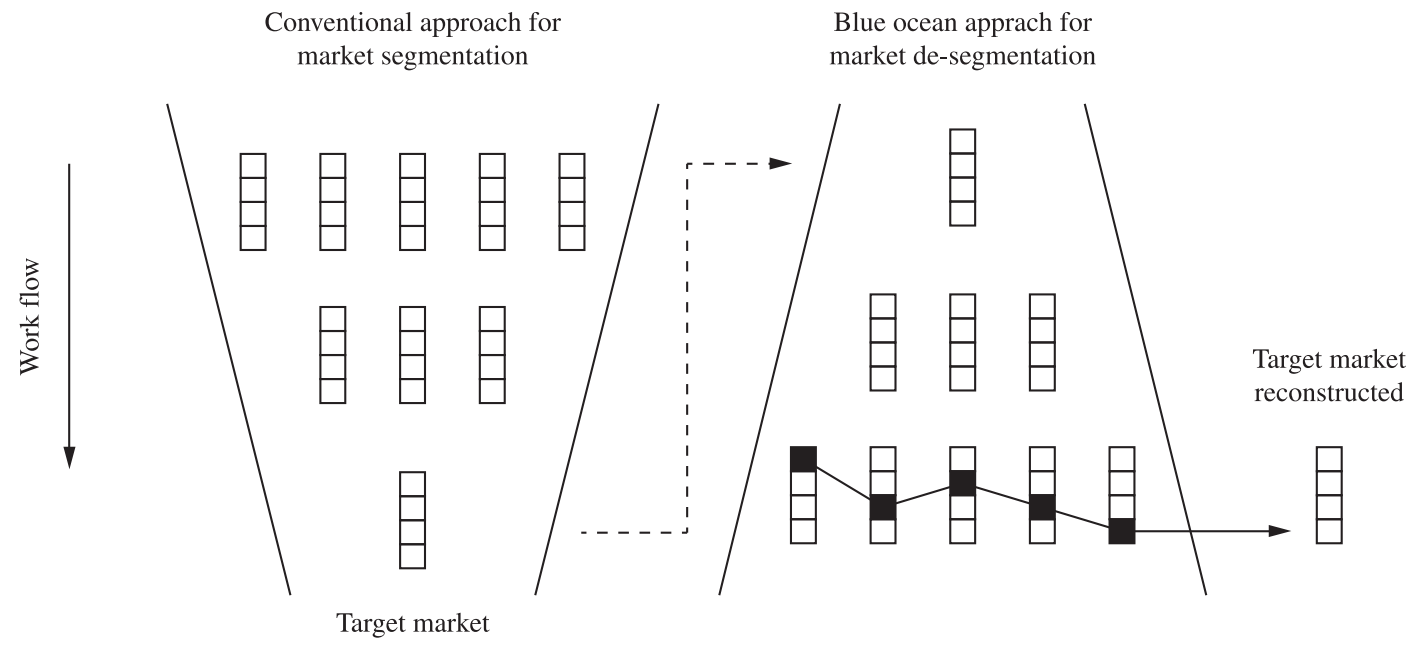

Figure 2. Approaches for segmentation and de-segmentation. 
as "identification of unexplored market space", by creating demand and opportunity for high profitable growth.

Kim and Mauborgne (2005) recommend exploring opportunities in the three levels of non-customers. Thus, the design team should contact customers and non customers. However, BOS does not signal how to perform this contact (i.e. applying the current marketing techniques?). From the analysis, it can be noticed that BOS needs to incorporate techniques for market research in its scope, as well as, mechanisms for generating and selecting ideas (e.g. SPP). A clear definition for the term "opportunity" is not presented.

Although the BOS book was published in 2005, few practical data are available, as well as scientific papers about it. The BOS is yet an evolving theme. The proposal from Kim and Mauborgne (2005) still remains unchallenged. However, several forums over the Internet present some divergent analysis on BOS results.

Owen (2009) treats BOS as one of the biggest myths of business in recent times. This author classifies it as a quick and superficial repair operation. Rao (2007) believes that the proposal can be dangerous because it embeds a false sense of security. Moreover, this author states that the risk analysis approaches are weak. Tru (2007) does not recommended for the SPP. Rao (2007) also comments that the tools presented can provide good results for a retrospective analysis, but are unsuitable for creating something new. Cooper and Edgett (2007) declare that some theories are excellent in explaining the past but are not very efficient to prospect the future. From that, it can be said that BOS falls into this category of approaches.

It is also believed that the BOS fits the category of theories difficult to reproduce experimentally and that can have its performance measured, as stated by Cooper and Edgett (2007), about the practices of open innovation, Lumpkin, Shrader and Hills (1998) regarding the effectiveness of planning practices and Gumpert (2002) concerning the use of business plans. According to these authors, the positive influence of these practices in business success has not yet been proved scientifically. Rao (2007) comments that the proposal by Kim and Mauborgne (2005) is also incontestable, since it cannot be tested properly. According to these author, even if the experiment is carefully controlled, it is not possible to know exactly the impacts derived from all variables involved. Besides its reproducibility, BOS lacks traceability, since the supporting references to the ideas presented are not mentioned. Rao (2007) has noted clear links with the theory of other authors not referred in the BOS book.

Science must be based on its rigour, relevance, reproducibility and traceability. Although the problem addressed by the BOS is relevant, it can be said to be scientific, as proposed Kim and Mauborgne (2005). However, this is not a characteristic unique to BOS. Kaplan and Norton (2008) comment that practices for strategy formulation are more related to art than science. According to Rao (2007), the challenge faced by BOS is the problem of creativity, which the proposed approach can not resolve. For Rao, the major BOS flaw, is to induce the belief that the BOS is appropriate.

Thus, besides the inference exposed, this research could neither find evidences capable of refuting the theory by Kim and Mauborgne (2005), nor those sufficient to endorse it. However, the authors' proposal was derived from publications approved by Harvard University Press, a company with international reputation. This is questioned by Tru (2007) which rejects the proposal and questions the reasons why such publications, including the book, are allowed. The internet is full of favorable comments to the proposal, but did not identify critical reliable sources besides those already mentioned. Next section, discussed relevant aspects from BOS that can be linked with SPP and PDP.

\subsection{Integration of BOS with SPP and PDP}

As seen in Kaplan and Norton (2008) the BOS is addressed in a specific phase of the SPP, named "the strategy formulation". It is also seen that, during the SPP are generated and evaluated ideas of new products, obtained via insights. In PDP, specifically in the process of Strategic Product Planning (SPrP), are gathered and evaluated the new product ideas, which are then improved and developed in other stages of the PDP. However, Kim and Mauborgne (2005) do not present clearly how to integrate the BOS with PDP. Based on the information collected and discussed in previous sections, it is inferred that the conventional relationship of BOS with the PDP occurs as shown in Figure 3.

The figure represents a possible integration of these approaches. As it is presented, BOS is capable of generating new product ideas. The SPP, that occurs before PDP is deployed, can be initiated with statements of new product ideas. Thus, these ideas could be linked between these theories and actual processes. However, this view is questionable.

Although the strategy is not supposed to define products but a proposition that adds value (among other issues within the company's scope, in a given context) the text by Kim and Mauborgne (2005) has several references to products and services that supposedly explore blue oceans. These elements in Kaplan and Norton (2008) are strategic initiatives that should be at the business units (or even during the product development), as suggested by the model from Rozenfeld et al. (2006). It can be noticed that BOS leads to a vision of a new value proposition, expressed by a curve of value which, according to Kaplan and Norton (2008), is the core of a well defined strategy. However, the Strategy Canvas is presented concerning products and services that 


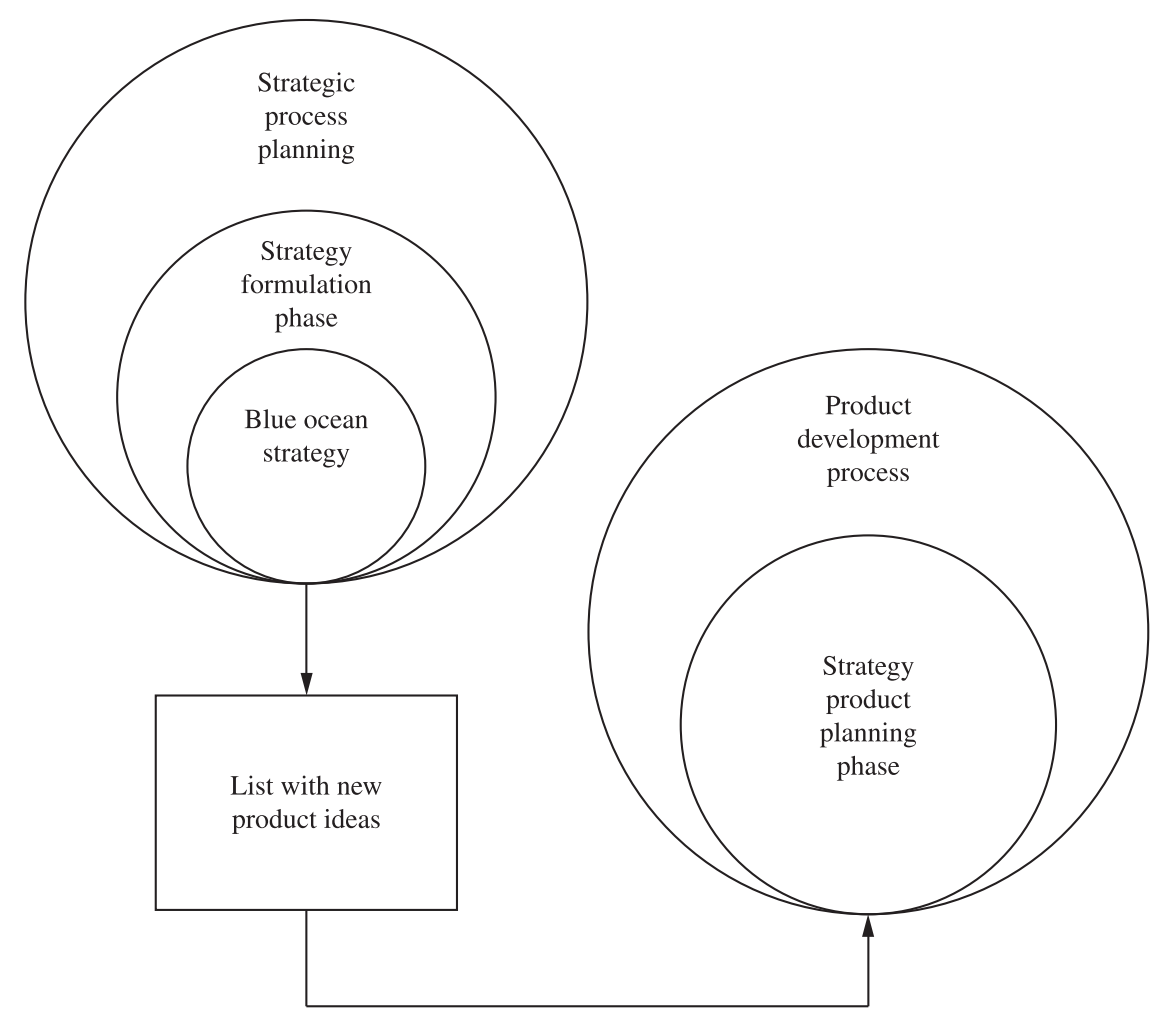

Figure 3. Schematic of integration of BOS into SPP and PDP.

are actually strategic initiatives (i.e. strategic projects). It is well known that a value proposition or a generic strategy, can lead to different strategic initiatives.

The PDP, in turn, has a set of methods and tools for generating ideas in the conceptual design phase, which is believed to be more robust than that suggested by BOS. In the references examined, it was not possible to identify clearly the level of detail and definition of these initial ideas for new products and what are the influences of these product definitions derived from the SPP, in the creativity process during the conceptual design stage. Only Pahl et al. (2005) commented that the principles of solution should be reassessed during conceptual design.

Another implication of the integration of these theories is the fact that they are not static. Some recommendations from BOS should follow the development of the value offers derived. When starting to consider non-customers, it is important to keep them in sight, during the following stages of development. Consulting lead-users, for example, should not be limited to the initial phases, as commented by Cooperand Edgett (2007). However, these recommendations for developing a value offer are not implemented by Kim and Mauborgne (2005).

\section{Discussion}

The research, as it was developed, aimed at being scientifically rigorous. However, it was not possible to collect practical evidences to support the analysis and preparation of definitive conclusions.

It was not possible to conduct an experiment to verify some of the questionings formulated. However, it was observed that, even if an experiment could be performed, it would be virtually impossible to measure only the results due to the large number of variables involving the SPP, PDP and BOS approach. The results discussed in this paper are based mainly in reference analyses (there are only two cases that claim to have evidence of practical BOS application (a company examined and a case study presented by the representatives of the BOS, in Brazil). However, it can be said that the number of BOS practitioners, as postulated by Kim and Mauborgne (2005), is small, despite the popularity of their literary work. The BOS community was reactive in participating in this research.

Additionally, it is observed that similarly to BOS, other management approaches also suffer from the same scientific soundness weaknesses. Works such as Annacchino (2007) that examines Business Process Development (BPD) and Kaplan and Norton (2008) for SPP and Cooper (2001) for PDP, should clarify some procedures for its full implementation. In general, these approaches signal "what" companies should do, instead of defining "how" the activities should be structured. Therefore, an analyses supported by the tools from scientific method poses several difficulties. 
One clear finding is that BOS systematic procedures presented leaves doubts over its practical implementation. Many guidelines needed for BOS application are diffuse and hidden in the cases presented, which difficults its complete understanding. Differently from PDP, BOS does not present a model for its integration with the process of opportunity development. On the other hand, the proposition of market de-segmentation is unique, since several PDP sources recommend a market segmentation approach.

\section{Closing remarks}

The BOS aims at identifying "blue oceans" in a systematic way. However, it is believed that BOS demands a substantial dose of business experience to be implemented. This limits the validity of the model envisaged by Kim and Mauborgne (2005) as originally proposed. Therefore, its scientific reliability is difficult to be assessed.

BOS can be mapped into SPP context. Additionally, it can provide information to the early stages of PDP, with new product ideas that can be called strategic initiatives (which are supposed to deploy the strategy formulated). This requires the existence of a system to capture and manage these ideas in order to consider them, during PDP when reviewing the company's portfolio.

BOS approach is unique when compared with those conventional means for identifying opportunities, since it involves restructuring markets and supply sectors. It is believed that, although the procedure presented by the authors is weak from the point of view of scientific reproducibility, the concepts presented can be fundamental for considering the opportunities to develop new products, involving differentiation and low cost simultaneously (in order to render the competition irrelevant). The subject motivates further research, especially surveys, with companies that claim to develop products applying BOS principles.

\section{Acknowledgements}

The support from PPGEM, at Federal University of Technology of Paraná State - Brazil, and CAPES for providing the scholarship for this research, are fully acknowledged. All the opinions, findings, conclusions and recommendations presented in this paper are the responsibility of the authors.

\section{References}

ANNACCHINO, M. A. The pursuit of new product development: the business development process. Burlington: Butterworth-Heinemann, 2007. 512 p.

BACK, N. et al. Projeto integrado de produtos: planejamento, concepção e modelagem. Barueri: Manole, 2008.
COOPER, R. G. Winning at new products: accelerating the process from idea to launch. 3rd ed. New York: Basic Books, 2001.

COOPER, R. G.; EDGETT, S. J. Generating breakthrough new product ideas: feeding the innovation funnel. New York: Product Development Institute, 2007.

FIET, J. O.; CLOUSE, V. G. H.; NORTON JUNIOR, W. I. Systematic search by repeat entrepreneurs. In: BUTLER, J. E. (Ed.). Opportunity identification and entrepreneurial behavior. Greenwich: Information Age Publishing, 2004. p. 1-27.

GUMPERT, D. E. Burn your business plan: what investors really want from entrepreneurs. Needham: Lauson Publishing Co., 2002.

KAPLAN, R. S.; NORTON, D. P. A execução premium. Rio de Janeiro: Elsevier, 2008.

KELLEY, T.; LITTMAN, J. As 10 faces da inovação: estratégias para turbinar a criatividade. Rio de Janeiro: Elsevier, 2007.

KIM, W. C.; MAUBORGNE, R. A estratégia do oceano azul: como criar novos mercados e tornar a concorrência irrelevante. 11. ed. Rio de Janeiro: Elsevier, 2005.

KIMBERLY-CLARK. Scott compacto. São Paulo: Kimberly-Clark Blue Ocean Strategy institute Brasil, 2009. Disponível em: <http://www.kcblueoceanstrategy.com. br/ cases_scott.asp > Acesso em: 16 set. 2009, 11:19:00.

KO, S. Bisociation and opportunity. In: BUTLER, J. E. (Ed.). Opportunity identification and entrepreneurial behavior. Greenwich: Information Age Publishing, 2004. p. 99-114.

KOEN, P. et al. Providing clarity and a common language to the "fuzzy front end". Research Technology Management, v. 44, n. 2, p. 46, Mar./Apr. 2001.

KOEN, P. A. et al. Fuzzy front end: effective methods, tools, and techniques. In: BELLIVEAU, P.; GRIFFIN, A.; SOMERMEYER, S. (Eds.). The PDMA toolbook 1 for new product development. New York: John Wiley \& Sons Inc., 2002. p. 5-35.

KOTLER, P.; KELLER, K. L. Administração de marketing. 12. ed. São Paulo: Pearson Prentice Hall, 2006.

LUMPKIN, G. T.; SHRADER, R. C; HILLS, G. E. Does formal business planning enhance the performance of new ventures? Babson College, 1998. Disponível em: $<$ http://www.babson.edu/entrep/fer/papers98/VII/VII_A/ VII_A.html>. Acesso em: 20 fev. 2007, 17:00:00.

MINTZBERG, H.; AHLSTRAND, B.; LAMPEL, J. Safári de estratégia: um roteiro pela selva do planejamento estratégico. Porto Alegre: Bookman, 2000. 
MINTZBERG, H et al. O processo da estratégia: conceitos, contextos e casos selecionados. 4. ed. Porto Alegre: Bookman, 2006.

OWEN, J. 10 of the biggest management myths. BNET United Kingdom, 2009. Disponível em: <http://blogs.bnet. co.uk/sterling-performance/2009/09/18/10-of-the-biggestmanagement-myths/> Acesso em: 22 set. 2009, 14:54:00.

PAHL, G. et al. Projeto na engenharia: fundamentos do desenvolvimento eficaz de produtos: métodos e aplicações. São Paulo: Edgard Blücher Ltda., 2005. Tradução da $6^{\mathrm{a}}$ edição alemã.

RAO, V. Book review: blue ocean strategy. Ribbonfarm, 2007. Disponível em: <http://www.ribbonfarm.com/2007/08/06/ book-review-blue-ocean-strategy/> Acesso em: 22 set. 2009, 15:04:00.

RIES, A.; TROUT, J. Posicionamento: a batalha por sua mente. São Paulo: Pearson Makron Books, 2002.
ROZENFELD, H. et al. Gestão de desenvolvimento de produtos: uma referência para a melhoria do processo. São Paulo: Saraiva, 2006. 542 p.

STULL, C.; MYERS, P.; SCOTT, D. M. Tuned in: uncover the extraordinary opportunities that lead to business breakthroughs. New Jersey: John Wiley \& Sons, Inc., 2008.

TROUT, J. O líder genial. Rio de Janeiro: Best Seller, 2005.

TROUT, J.; RIVKIN S. Diferenciar ou morrer: sobrevivendo em uma era de competição mortal. São Paulo: Futura, 2000.

TRU. Blue ocean strategy: ocean strategy, red or blue, belongs in the dead sea. Tucson: TRU Group Inc., 2007. Disponível em: <http://trugroup.com/TRU-blue-ocean-strategy.html>. Acesso em: 22 set. 2009, 23:44:00.

URBAN, G. L.; HAUSER, J. R. Design and marketing of new products. New Jersey: Prentice-Hall, 1993. 